\title{
TEXTO E DISCURSO
}

\author{
Eni Puccinelli Orlandi
}

RESUMO: Texte est un objet linguistique-historique qui établit des rapports avec soi même et l'exteriorité. C'est à dire: le texte est à la fois un objet empirique, doué de commencement, développement et fin, et un objet discursif caractérisé par l'incompletude. Il est donc en rapport avec son extériorité constitutive, l'interdiscours, qui représente la mémoire du dire. C'est à partir de cette historicité du texte qu'il est possible de travailler et d'interpréter la trame de sens qui s'y établit. Dans ce sens, texte est une unité d'analyse affectée par ses conditions de production.

PALAVRAS-CHAVE: texto, discurso, análise do discurso, interdiscurso, objeto lingüístico-histórico, objeto simbólico, materialidade histórica da linguagem, historicidade do texto, incompletude, trama de sentidos.

\section{INTRODUÇÃO}

Eu começaria por dizer que o texto é uma peça de linguagem, uma peça que representa uma unidade significativa.

Não hesitaria, como aliás tenho feito há anos nos meus cursos de Introdução à Análise de Discurso, em começar a reflexão partindo de M. A. K. Halliday na enfatização de ser o texto a unidade primeira. Para ser texto, diz ele (1976), é preciso ter textualidade. E a textualidade é função da relação do texto consigo mesmo e com a exterioridade. Mas, embora as inversões que ele propõe (texto >sentenças; sentido>dizer, etc.) sejam muito a meu gosto, a exterioridade não tem em Halliday nem a mesma natureza, nem o mesmo estatuto que tem na análise de discurso (E. ORLANDI, 1992).

Passando, pois, para a minha filiação teórica específica, eu diria que as palavras não significam em si. É o texto que significa.

Quando uma palavra significa é porque ela tem textualidade, ou seja, porque a sua interpretação deriva de um discurso que a sustenta, que a provê de realidade significativa.

Eni Puccinelli Orlandi é professora no IEL da Universidade Estadual de Campinas

${ }^{1}$ Peça aqui está mais para peça de teatro que para engenhoca, embora a ambigüidade seja produtiva. 
É assim que, na compreensão do que é texto, podemos entender a relação com o interdiscurso, a relação com os sentidos (os mesmos e os outros).

Mas posso chegar mais perto daquilo que é minha proposta na análise da linguagem: o texto é um objeto histórico. Histórico aí não tem o sentido de ser o texto um documento, mas discurso. Assim, melhor seria dizer: o texto é um objeto lingüístico-histórico. É a partir dessa definição que tenho procurado entender o que é o texto para a análise de discurso francesa.

Acho interessante aproveitar esta oportunidade para explicitar melhor o que é o (lingüístico) histórico para o analista de discurso.

Afirmando que seria um erro considerar a análise de discurso, tal como ele a concebe, simplesmente como o exercício de uma nova lingüística livre dos preconceitos da lingüística tradicional, M. Pêcheux (1975) dirá que o discurso introduz um descentramento na própria linguiística. Esta mudança, portanto, não reside, como ele diz $(i d$.), num outro modo de abordar seu objeto, dentro de novas necessidades impostas pela pesquisa, etc. A especificidade da análise de discurso está em que o objeto a propósito do qual ela produz seu resultado não é um objeto lingüístico, mas um objeto sociohistórico onde o lingüístico intervém como pressuposto. Há, pois, diz ainda ele (ibid.), um efeito de separação-clivagem entre a prática lingüística e a análise de discurso. Segundo Pêcheux é, pois, abuso de linguagem o uso do termo lingüística do discurso para designar, de fato, uma linguística dos textos quando ela ultrapassa o domínio da análise da frase, muitas vezes recoberta, por outro lado, pela expressão lingüística da fala. A análise concreta de uma situação concreta pressupõe que a materialidade discursiva em uma formação ideológica seja concebida como uma articulação de processos (PÊCHEUX, ibid.). A este respeito, Pêcheux remete à observação de P. Fiala e C. Ridoux (1973, p.45): o texto — diríamos o discurso - não é um conjunto de enunciados portadores de uma, e até mesmo várias significações. É antes um processo que se desenvolve de múltiplas formas, em determinadas situações sociais.

Se estas considerações nos colocam já em situação de compreender a natureza do social, que é levado em conta na análise de discurso, outras observações se impõem a fim de tornar mais preciso esse campo de distinções. Essas observações dizem respeito ao fato de que, na AD (análise de discurso da escola francesa), tenho preferido falar não em história mas em historicidade do texto.

Ao longo de meu trabalho tenho colocado já repetidas vezes que um texto, do ponto de vista de sua apresentação empírica, é um objeto com começo, meio e fim, mas que se o considerarmos como discurso, reinstala-se imediatamente sua incompletude. Dito de outra forma, o texto, visto na perspectiva do discurso, não é uma unidade fechada - embora, como unidade de análise, ele possa ser considerado uma unidade inteira - pois ele tem relação com outros textos (existentes, possíveis ou imaginários), com suas condições de produção (os sujeitos e a situação), com o que chamamos sua exterioridade constitutiva (o interdiscurso: 
a memória do dizer).

\section{HISTÓRIA E HISTORICIDADE}

A AD é um marco na história das idéias lingüísticas em uma mudança que toca essa distinção entre história e historicidade que estamos propondo para a reflexão.

No século XIX, a noção de história relacionada à língua a atomizava, vendo nessa relação uma dimensão temporal expressa na forma da cronologia e da evolução.

A fundação da lingüística, com a noção de língua como sistema, já não pode acolher esta concepção de história e tampouco a de língua como seu produto.

São várias as tentativas de ajuste, de adaptação — através da elaboração de noções como a pancronia, a relação temporal entre diferentes estados do sistema, etc. —, mas elas acabam sempre por colocar a história como algo exterior, complementar ou em relação de causa e efeito com o sistema lingüístico.

Com a $\mathrm{AD}$ - e isto que estamos chamando historicidade - a relação passa a ser entendida como constitutiva. Desse modo, se se pode pensar uma temporalidade, essa é uma temporalidade interna, ou melhor, uma relação com a exterioridade tal como ela se inscreve no próprio texto e não como algo lá fora, refletido nele. Não se parte da história para o texto —avatar da análise de conteúdo - se parte do texto enquanto materialidade histórica. A temporalidade (na relação sujeito/sentido) é a temporalidade do texto.

Não se trata assim de trabalhar a historicidade (refletida) no texto, mas a historicidade do texto, isto é, trata-se de compreender como a matéria textual produz sentidos.

São, pois, os meandros do texto, o seu acontecimento como discurso, a sua mise-en-øuvre, como dizem os franceses, ou como podemos dizer, o trabalho dos sentidos nele, que chamamos historicidade.

Claro que há uma ligação entre a história lá fora e a historicidade do texto (a trama de sentidos nele), mas ela não é nem direta, nem automática, nem de causa e efeito, e nem se dá termo-a-termo. É, pois, preciso admitir que esta relação é mais complexa do que pretendem as teorias da literalidade e que deixam pensar que a análise de discurso que eu pratico vê nos textos os conteúdos da história.

Nesse sentido é que tenho afirmado que, entre a evidência empírica e a certeza do cálculo formal, há uma região menos visível, menos óbvia, mas igualmente relevante, que é a da materialidade histórica da linguagem. O texto pode ser um bom lugar para se refletir sobre isso.

Pela análise da historicidade do texto, isto é, do seu modo de produzir sentidos, podemos falar que um texto pode ser - e, na maioria das vezes, o é efetivamente - atravessado por várias formações discursivas. É nesse sentido que falei — mesmo antes de conhecer os trabalhos de J. Authier (1984) - em 
heterogeneidade do discurso (E. ORLANDI \& E. GUIMARÃES, 1988). Nesse trabalho, já propúnhamos que se considerasse a relação proporcional texto:discurso::autor:sujeito, como uma relação que se fazia da unidade para a dispersão (e vice-versa), no sentido de produzir uma relação consistente entre linguagem e história.

Também em minha distinção entre "inteligibilidade, interpretabilidade e compreensão" (E. ORLANDI, 1988, p.101), está dito que a compreensão é a apreensão das várias possibilidades de um texto. Para compreender, o leitor deve se relacionar com os diferentes processos de significação que acontecem no texto. Esses processos, por sua vez, são função da historicidade, ou seja, da história do sujeito e do sentido do texto, enquanto discurso. Sem esquecer que o discurso é estrutura e acontecimento (M. PÊCHEUX, 1983), o objetivo da AD é compreender como um texto funciona, como ele produz sentidos, sendo ele concebido enquanto objeto lingüístico-histórico.

Eis outra via possível de se pensar a historicidade na perspectiva em que a estamos colocando: história do sujeito e do sentido. Inseparáveis: ao produzir sentido, o sujeito se produz, ou melhor, o sujeito se produz, produzindo sentido. É esta a dimensão histórica do sujeito — seu acontecimento simbólico — já que não há sentido possível sem história, pois é a história que provê a linguagem de sentido, ou melhor, de sentidos ${ }^{2}$. Daí o equívoco como condição do significar, sendo o mais importante deles o que cria a ilusão referencial, a da literalidade.

Não se pode falar em anterioridade de sentido, seja na estrutura, seja no acontecimento. O sentido se dá no encontro dos dois, na sua relação. Daí uma das muitas maneiras de se entender a afirmação de Canguilhen (1980) de que o sentido é relação $a$.

Pois bem, podemos assim dizer que, na $\mathrm{AD}$, a historicidade é função da necessidade do sentido no universo simbólico.

O texto é justamente esse objeto (lingüístico) histórico, se o pensamos como essa unidade que se estabelece pela historicidade enquanto unidade de sentido.

\section{DA ANÁLISE}

Não nos interessa, nessa perspectiva discursiva, a organização do texto. O que nos interessa é o que o texto organiza em sua discursividade, em relação à ordem da língua e a das coisas: a sua materialidade.

Quando dizemos que o texto é uma unidade significativa, estamos afirmando que a ordem da língua está ali, enquanto sistema significante. Mas não apenas isso.

\footnotetext{
2 Tendo que traduzir isto para o inglês, para uma comunicação em Lancaster, alarguei minha compreensão desse processo já que a tradução exigia precisão: "The history provides language of senses".
}

114 
Referimos mais acima que a história afeta a linguagem de sentidos. Desse encontro resulta o texto, logo textualidade que é história, que faz sentido.

A AD procura trabalhar nesse lugar particular em que se encontram a ordem da língua e a ordem da história.

A noção que resulta mais clara, na observação do encontro dessas ordens na análise da linguagem, é a noção de fato que, por sua vez, deriva de um deslocamento produzido sobre a noção de dado (E. ORLANDI, 1992).

$\mathrm{O}$ dado tem sua organização, o fato se produz como um objeto da ordem do discurso (lingüístico-histórico).

Na perspectiva dessa relação dado/fato, quando afirmo que um texto não é um documento, mas um discurso, estou produzindo algo mais fundamental: estou instalando na consideração dos elementos submetidos à análise - no movimento contínuo entre descrição e interpretação - a memória. Em outras palavras, os dados não têm memória, são os fatos que nos conduzem à memória lingüística. Nos fatos, temos a historicidade. Observar os fatos de linguagem vem a ser considerálos em sua historicidade, enquanto eles representam um lugar de entrada na memória da linguagem, sua sistematicidade, seu modo de funcionamento. Em suma, olharmos o texto como fato, e não como um dado, é observarmos como ele, enquanto objeto simbólico, funciona.

Como o texto é o fato de linguagem por excelência, os estudos que não tratam da textualidade (discursividade) não alcançam a relação com a memória da língua.

Essas considerações nos permitem afirmar que o texto é uma unidade complexa - um todo que resulta de uma articulação - representando assim um conjunto de relações significativas individualizadas ${ }^{3}$ em uma unidade discursiva. A individualização dessas relações é que pode ser apreciada através da noção de heterogeneidade (diferença), tal como a definimos mais acima. E isto é fundamental para a análise do texto.

O texto é heterogêneo:

1. Quanto à natureza dos diferentes materiais simbólicos: imagem, grafia, som, etc.

2. Quanto à natureza das linguagens: oral, escrita, científica, literária, narrativa, descrição, etc.

3. Quanto às posições do sujeito.

4. Além disso, podemos trabalhar essas diferenças em termos de formações discursivas (FD). Nesse caso, temos um princípio importante que é o de que um texto não corresponde a uma só $\mathrm{FD}$, dada a heterogeneidade que o constitui, lembrando que toda FD é heterogênea em relação a si mesma (COURTINE, 1982).

Suponhamos que o analista esteja trabalhando com o discurso feminista e que ele o caracterize como a FDx, com sua configuração própria, onde $\mathrm{x}=$

\footnotetext{
${ }^{3}$ Individualização aqui deve ser entendida no sentido em que Foucault diz que há diferentes formas de individualização dos sujeitos nas diferentes formações sociais.
} 
feminista.

$\mathrm{Na}$ análise, ele disporá de uma multiplicidade de textos que ele pode considerar no conjunto de textos que dizem respeito a Fdx: o texto 1, o texto 2, o texto 3. Estes textos, por sua vez, estarão atravessados por diferentes FD:FDx, mas também FDz, FDn, FDa, FDb, FDy, já que os textos são heterogêneos em relação às $\mathrm{FD}$ que os constituem.

Podemos ter a seguinte configuração gráfica, pensando a heterogeneidade de cada texto, no conjunto dos textos submetidos à análise:

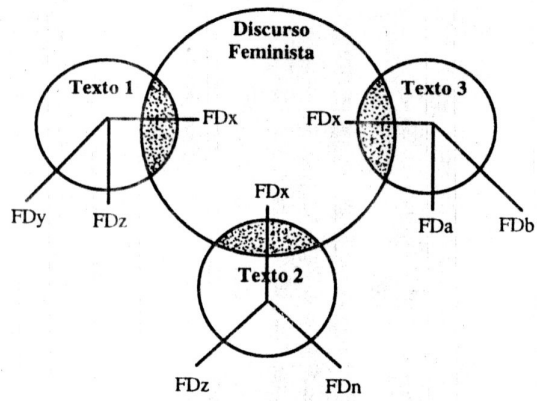

A heterogeneidade do discurso feminista resulta assim do fato de que, no texto 1, a FDx convive com FDz e FDy, no texto 2, convive com FDa e FDb, e no texto 3, com FDz e FDn. Essas diferentes relações produzem efeitos de sentidos diferentes, o que terá de ser levado em conta neste discurso.

Portanto, na dispersão de textos que constituem um discurso, a relação com as FD em suas diferenças é elemento fundamental que constitui o que estamos chamando de historicidade do texto.

São vários os procedimentos de análise - como relação de paráfrases, observação dos diferentes enunciados de ocorrência, relação com diferentes discursos, etc. —, mas qualquer que seja o procedimento, o ponto de partida é sempre o mesmo na relação entre unidade e dispersão: o postulado de que o sentido sempre pode ser outro e o sujeito (com suas intenções e objetivos) não tem o controle daquilo que está dizendo.

Isto nos leva a duas ordens de conclusões também muito importantes:

1. Um sujeito não produz só um discurso

2. Um discurso não é igual a um texto.

Daí que a relação proposta na $\mathrm{AD}$ é:

a. Remeter o texto ao discurso

b. Esclarecer as relações deste com as FD, pensando as relações destas com a ideologia.

A AD está assim interessada no texto não como objeto final de sua explicação, mas como unidade que lhe permite ter acesso ao discurso. $\mathrm{O}$ trabalho do analista é percorrer a via pela qual a ordem do discurso se materializa na 
estruturação do texto.

O texto, dissemos inúmeras vezes, é a unidade de análise afetada pelas condições de produção. O texto é, para o analista de discurso, o lugar da relação com a representação física da linguagem: onde ela é som, letra, espaço, dimensão direcionada, tamanho. É o material bruto. Mas é também espaço significante. E não é das questões menos interessantes a de procurar saber como se põe um discurso em texto.

\section{CONCLUSÃO}

Na perspectiva do discurso, o texto é lugar de jogo de sentidos, de trabalho da linguagem, de funcionamento da discursividade (cf. E. ORLANDI, 1983, p.204205).

Como toda peça de linguagem, como todo objeto simbólico, o texto é objeto de interpretação. Para a $\mathrm{AD}$, esta sua qualidade é crucial. É sua tarefa compreender como ele produz sentido e isto implica compreender tanto como os sentidos estão nele quanto como ele pode ser lido. Esta dimensão, eu diria ambígua, da historicidade do texto, mostra que o analista não toma o texto como o ponto de partida absoluto (dada a relação de sentidos), nem como ponto de chegada.

Quando se trata de discurso, não temos origem e não temos unidade definitiva. Um texto é uma peça de linguagem de um processo discursivo muito mais abrangente.

Feita a análise, não é sobre o texto que falará o analista, mas sobre o discurso. Uma vez atingido o processo discursivo, que é o que faz o texto significar, o texto, ou os textos particulares analisados desaparecem como referências específicas para dar lugar à compreensão de todo um processo discursivo do qual eles - e outros que nem mesmo conhecemos — são parte. Sem esquecer que todo dizer, discursivamente, é um deslocamento nas redes de filiações (históricas) de sentidos (PÊCHEUX, 1983).

Não são, pois, só aqueles textos os responsáveis pelos processos de significação que se atinge. Eles tampouco estão relacionados só aos processos que eram objeto de sua análise. Desse modo, não só não existe relação termo-a-termo entre a linguagem e o mundo como também não existe relação termo-a-termo entre os textos que são os materiais de análise e os resultados dela. A mediação da própria análise, da teoria e dos objetivos do analista são parte da construção do texto como unidade da análise. Isto é também parte da historicidade. E é nesse sentido que dizemos que o corpus não é nunca inaugural em AD. Ele já é uma construção (fato).

Esta talvez seja a melhor maneira de argumentar contra as posições positivistas. Não pela referência à ilusão da evidência das marcas, mas pela lembrança de que esses objetos que são nossos materiais de análise só o são em sua 
provisoriedade. A duração dos textos é trabalho do arquivo ${ }^{4}$.

\section{BIBLIOGRAFIA}

AUTHIER, J. Hétérogénéités Enonciatives. Langages, Larousse, Paris, 1984.

COURTINE, J. J. La Toque de Clementis. Paris, 1982.

HALLIDAY, M. A. K.; HASAN. Cohesion in English. Longman, Londres, 1976.

ORLANDI, E. A Linguagem e seu funcionamento. Brasiliense, São Paulo, 1983.

ORLANDI, E.; GUIMARÃES, E. Unidade e Dispersão: uma questão do sujeito e do discurso. Discurso e Leitura. São Paulo/Cortez, Campinas/Ed. da UNICAMP, 1988.

ORLANDI, E. Discurso: fato, dado, exterioridade. In: SEMINÁRIO DE AQUISIÇÃO, 1992. (No prelo).

PÊCHEUX, M. Les Vérités de Ia Palice. Maspero, Paris, 1975.

PÊCHEUX, M. Discours: Structure ou Evennement? (Traduzido por Eni Orlandi. Discurso: estrutura ou acontecimento? Campinas, Pontes, 1990.). Illinois, University Press, 1983.

${ }^{4}$ Arquivo aqui está sendo usado no sentido da AD. Para compreender esta noção cf. Gestos de Leitura, E. ORLANDI et alii, Ed. Unicamp, 1994. 